\title{
The Role of Counterparty Risk in CHAPS Following the Collapse of Lehman Brothers*
}

\author{
Evangelos Benos \\ Financial Stability, Bank of England University of California, Santa Barbara \\ Peter Zimmerman \\ Financial Stability, Bank of England
}

May 20, 2013

\begin{abstract}
We study the impact of the global financial crisis on CHAPS, the United Kingdom's largevalue wholesale payments system, over the period 2006-2009. Payments data show that in the two months following the Lehman Brothers failure, banks did, on average, make payments at a slower pace than before the failure. We show that this slowdown is related to concerns about counterparty default risk, thereby identifying a new channel through which counterparty risk manifests itself in financial markets.
\end{abstract}

Keywords: Intraday liquidity, Payments, Credit default swap, Counterparty risk.

JEL code: E42

\section{Introduction}

During the intense period of financial turmoil in the wake of the Lehman Brothers default, infrastructures used by banks to make payments to one another held up well. Bank of England 2009 explains that although the crisis placed unprecedented demands on payment and settlement systems, they continued to provide a robust service. Although disruption did not materialise, it is nevertheless imperative, given the crucial importance of payment systems, to understand whether and to what extent heightened uncertainty about the solvency of banks worldwide impacted the behavior of banks operating within these systems and whether changes in behavior led to elevated risks.

In this paper we study the behavior of banks operating in CHAPS (Clearing House Automated Payment System), the United Kingdom's large-value wholesale system for unsecured payments.

${ }^{*}$ This paper is based on material from Bank of England Working Paper \#451 by the same authors. The views expressed in this paper are those of the authors, and not necessarily those of the Bank of England. We are grateful to the Harrison Hong and an anonymous referee of this Journal. We also wish to thank Viral Acharya, Paul Chilcott, Toby Davies, James Goodfellow, Lavan Mahadeva, Jamie McAndrews, Edwin Schooling Latter, Anne Wetherilt, Filip Žikeš, an anonymous referee for the Bank of England working paper series and seminar participants at the Bank of England, Federal Reserve Bank of New York, De Nederlandsche Bank and National Bank of Serbia for useful comments and suggestions.

${ }^{\dagger}$ Corresponding author: Department of Economics, University of California, Santa Barbara, 93106 email:garratt@econ.ucsb.edu 
This is the system through which qualified private banks - called settlement banks - fulfill customer obligations and engage in their own money market activity. Typical payments can be related to financial market transactions, the sterling leg of foreign exchange trades, and UK house purchases. Some of these payments, such as foreign exchange transactions, are very time sensitive and must be executed immediately. ${ }^{1}$ For most payments, however, the bank has some discretion in terms of when it chooses to process the payment.

In deciding when to process a payment a bank must trade off the costs of providing liquidity to make the payment with the cost of delay. In CHAPS, banks acquire liquidity to make payments by using their reserves balances and by borrowing funds from the BoE at zero marginal cost, secured by posting BoE-eligible collateral to their central bank account. ${ }^{2}$ The cost of liquidity is therefore the opportunity cost of putting these funds into other productive (interest earning) uses. Banks do not have to fund all of their payments directly, however. Liquidity is recycled throughout the day as banks use incoming payments to fund outgoing ones. To save on liquidity costs a bank can attempt to delay its outgoing payments and use more liquidity from others. However delay itself has a cost, which may be explicit or implicit. Contracts underlying the payments may have explicit penalties for late delivery, particularly when the payment is not executed on the day it is initiated, and banks that fail to process payments in a timely fashion may incur reputational costs (see Bech and Soramäki 2001, Bech and Garratt 2003, and Galbiati and Soramäki 2011).

We begin our analysis by documenting a dramatic slowdown in payment processing following the collapse of Lehman Brothers. This is a significant event because timely processing is needed to complete the large volume and value of transactions that must be completed during a day. ${ }^{3}$ If one bank delays making payments to another, then the receiving bank may choose to delay some o.f its own payments, rather than use more of its own liquidity. In a worst case scenario, the system can fall into gridlock whereby payment processing grinds to a halt system wide. Such an event, though unprecedented, would represent a serious financial stability concern. Even without gridlock, processing delay raises overall liquidity costs, by lowering the rate at which liquidity in the system can be recycled, and elevates risks associated with operational outages or bank failures (see Benos et al. 2012). ${ }^{4}$

Our measure of delay is based on the deviation of observed aggregate throughput — the rate at which payments are made during the day - following the collapse of Lehman Brothers from the pre-collapse average. Deviations in payment throughput below the benchmark represent "delay", while positive deviations represent an "acceleration". We find that aggregate delay in CHAPS increased substantially in the wake of the Lehman Brothers default. In the two-month period of September and October 2008, delay attained a maximum average daily value of about 25 minutes (an increase by three standard deviations), meaning on average throughout the day, payments were made 25 minutes later than usual. Strikingly, this is the exact same amount by which aggregate delay increased in Fedwire as well, over the same period (Bech and Garratt 2012).

What caused the delay? Liquidity available to banks to make payments fluctuated significantly in the first few months following the collapse of Lehman Brothers (see Benos et al. 2012), but stocks stayed well above the amounts actually used to make payments. This suggests that other factors were driving banks' decisions to slow down payments. We conjecture that the motives

\footnotetext{
${ }^{1}$ Ball et al. 2011 suggests that around $4 \%$ of payments by value may be time sensitive.

${ }^{2}$ The list of eligible assets is restricted to highly liquid and safe securities, such as high-quality sovereign debt. See Bank of England 2010.

${ }^{3} \mathrm{~A}$ typical payments day in CHAPS involves over one-hundred thousand transactions with a value roughly equal to one-fifth of annual GDP. See Bank of England 2009.

${ }^{4}$ Operational outages are incidents where a settlement bank is unable to send payments due to a system failure.
} 
for delay relate to increased perceptions of counterparty risk. ${ }^{5}$ This conjecture is in line with the analysis of Bech and Garratt 2008 and Bech and Garratt 2012, who argue that heightened credit risk increases the expected cost of early processing and reduces the expected cost of delay, leading to a slowdown in payment processing. The increased expected cost results from the fact that payments made to a bank that becomes insolvent may not be fully recovered. And even if they are eventually recovered, the time taken in doing so can result in a liquidity shortfall for the sender on the day of the default, which may have to be made up by borrowing from the discount window. Therefore, if a bank thinks that the receiver of a payment is at risk of defaulting during the day it may not want to send payments to that bank in advance of payments which it expects to receive. In the event of a counterparty failure, a bank might prefer to net its obligations on its own books rather than attempt to recover funds through bankruptcy proceedings. ${ }^{6}$ The reduction in delay costs is based on the premise, articulated in Bech and Garratt 2003, that there will be smaller reputation costs associated with delaying payments to a troubled bank. Another source of delay stems from the tiered structure of the payment system in the United Kingdom. Many of the settlement banks process payments on behalf of client banks which are not CHAPS members themselves. ${ }^{7}$ If a settlement bank thinks that one of its clients might default during the day, then it may delay making that client's payments for the same reasons; it does not want to pay money out in advance of incoming funds which may be withheld if the client defaults. Furthermore, it may reduce the client's overdraft limit, meaning it is more likely to wait for incoming payments to the client before sending.

To examine if there is a (causal) link between counterparty risk and payment delay, we exploit the cross-sectional dimension of our sample and test if delay is targeted toward banks with higher credit risk, as measured by the premia of CDS contracts traded on their names. We estimate a dynamic panel specification of bank-specific delay over a time period immediately after the collapse of Lehman Brothers. We choose this time period because the default of Lehman was an event that heightened counterparty risk concerns and which, in turn, may be expected to cause banks to delay their payments. In our empirical tests we control for a number of other factors that could also potentially influence delay, such as the cost of liquidity, the actual amount of liquidity available and the existence of any bilateral credit limits between CHAPS banks. We find that counterparty risk is indeed associated with payment delay: an increase in a bank's CDS premium by one standard deviation (roughly $0.6 \%$ ) causes the rest of the banks to delay payments to it by about 2.5 minutes, on average, across the day.

The estimated impact of counterparty risk on delay is statistically significant, but it is questionable whether or not it is economically significant. In other words, the risk channel exists, but it may not be consequential. However, it is important to bear in mind that the crisis period saw increases in some CDS premia by several standard deviations and that we estimate an average effect which could be hiding larger fluctuations. Moreover, even small delays in incoming payments can result in banks having to use more of their own liquidity. One indication that behavioral changes following the collapse of Lehamn had large impacts is the $30 \%$ drop in turnover that occurred immediately following this event. Turnover is computed as the ratio of payments made to liquidity used. It therefore reflects the average number of times each pound of liquidity provided by a bank to make payments is used during the day. We show that turnover fell sharply from a daily average of around 15 to a daily average close to 11 following the collapse of Lehman.

\footnotetext{
${ }^{5}$ Recent work on the impact of counterparty risk on other financial markets includes Singh and Aitken 2009, who document a reduction in global liquidity since the end of 2007, and Heider et al. 2009 who study liquidity hoarding and the breakdown of interbank markets in the presence of counterparty risk.

${ }^{6}$ More details on this process can be found in Manning et al. 2009.

${ }^{7}$ Bank of England 2009, section 3.1.
} 
We do a series of robustness checks. CHAPS is a highly tiered payment system, meaning that only a few "first-tier" settlement banks participate directly in it. The first-tier banks act as correspondents and facilitate payments for the other banks. This implies that some of the observed payment flows between first-tier banks are actually directed toward second-tier banks, and so delay may potentially also reflect the credit risk of these second-tier banks. For this reason, we also estimate a specification where we control for second-tier bank credit risk. We find that while first-tier bank credit risk remains significant, second-tier bank credit risk does not influence delay. We explain that this is probably due to the unsecured bilateral credit limits extended from firsttier banks to their customer second-tier banks, which effectively allow second-tier banks to make payments using the available liquidity of their first-tier corresponding bank up to these limits. Finally, we also estimate our specification using an alternative measure of credit risk. Since trading in the CDS market is concentrated around few major financial institutions who act as dealers and because the credit risk of these dealers is likely highly correlated with the credit risk of the CHAPS banks, ${ }^{8}$ the premia of CDS contracts of the CHAPS banks may well reflect the joint probability of default of the reference entity and the contract seller. In that case, we would be measuring the CHAPS banks' credit risk with an error. For this reason, we also use an alternative Merton-type measure of default risk and we find that this alternative measure of credit risk retains its significance over delay.

The plan for the rest of paper is as follows. In Section 2 we go over the institutional characteristics of CHAPS. In Section 3 we describe the data used in the analysis. We begin the formal analysis in Section 4 and establish that payments were, in fact, delayed following the collapse of Lehman Brothers. In Section 5 we conduct our main empirical analysis in which we establish the importance of counterparty risk as a determinant of delay. In Section 6 we illustrate the drop in turnover following the collapse of Lehman brothers. In Section 7 we provide concluding remarks.

\section{Institutional Details of CHAPS}

CHAPS (Clearing House Automated Payment System) is the United Kingdom's large-value interbank payment system. Like most such payment systems it features real-time gross settlement (or RTGS) meaning that offsetting payment obligations cannot be netted and must instead be pre-funded. The participating CHAPS banks (or settlement banks) during the overall period of our sample (1 January 2006 to 12 February 2009) were: ABN Amro, Bank of England, Bank of Scotland, Barclays, Citibank, Clydesdale, Co-operative Bank, CLS Bank, Deutsche Bank, Lloyds, HSBC, Natwest, RBS, Santander/Abbey, Standard Chartered and UBS. Membership is not constant throughout our sample period: UBS joined on 8 October 2007 and ABN Amro left on 19 September 2008. Of these banks, the Bank of England and CLS Bank are not considered commercial institutions in the way that the others are.

CHAPS is mainly used to settle large-value payment instructions of banks' customers (such as payments for house purchases) and is also used to settle interbank money market transactions. In addition, many of the direct ("first-tier") CHAPS participants process payments on behalf of client ("second-tier") banks which are not CHAPS members themselves. ${ }^{9}$ These customer banks send their payment instructions to their first-tier correspondent banks which in turn make payments on their behalf. Any outstanding obligations between a first-tier and a customer bank, are settled at the end of the day; thus first-tier banks effectively extend unsecured, intraday credit to their

\footnotetext{
${ }^{8}$ Indeed, some of the CHAPS banks are also major CDS dealers.

${ }^{9}$ Bank of England 2009, section 3.1.
} 
second-tier clients.

For the most part, banks do not have a choice whether or not to make a payment on a given day. However, in many cases they have some discretion when, during the day, to make a payment. Exceptions are time-critical payments such as CLS payments or those that need to be made before certain markets close (Ball et al. 2009). Banks have an incentive to conserve liquidity because funds that banks deposit in their settlement accounts to facilitate payments have an opportunity cost to the bank in terms of foregone investment opportunities. In order to help ensure timely payment processing CHAPS settlement banks face throughput guidelines during the day. This means that they are expected to make a certain proportion of their daily values by certain times - at the time this was $50 \%$ by noon and $75 \%$ by $2.30 \mathrm{pm}$. However, these guidelines applied only on average over the course of the month and therefore did not necessarily restrict the payment behavior of banks on a given day. Additionally, the punishment for deviation from the guidelines may have been seen as weak.

CHAPS banks acquire liquidity to make payments by using their reserves balances ${ }^{10}$ and by borrowing funds from the BoE secured by posting BoE-eligible collateral to their central bank account. ${ }^{11}$ Thus, except for posting collateral, CHAPS banks do not incur any additional cost in order to borrow intraday from the BoE. Secured overnight loans are priced at the BoE policy rate. As is usual in RTGS payment systems, CHAPS banks do not have to fund all of their payments directly: they can recycle liquidity by using incoming payments to fund outgoing ones. Nevertheless, the ability of banks to make payments is, at least in aggregate terms, related to the amount of reserves and collateral posted.

\section{Data}

We use data on payments, collateral posted and settlement account balances (reserves) for all CHAPS settlement banks from 1 January 2006 to 12 February 2009. The end of the sample period was determined by data availability issues at the time this paper was initiated, and by the fact that in March 2009 reserve targeting was suspended by the Bank of England and quantitative easing was initiated. This led to an almost threefold increase in settlement banks' reserves with profound effects on bank payment behavior (see Benos et al. 2012). The payments, collateral and account data are obtained from the payments database maintained by the Bank of England in its role as operator of the RTGS system. We aggregate any figures that are reported separately for Natwest and RBS, since these banks belong to the same group.

We also use daily CDS premia from Bloomberg for several CHAPS settlement banks and their second-tier customers. We use average CDS premia for senior debt with maturity of 5 years as this is the most traded term and therefore should have a price which most accurately reflects the market's view of default risk. CDS are traded for each of the CHAPS settlement banks relevant to our analysis, with the exception of the Co-Operative Bank. There are no credit default swaps which reference CLS Bank or Bank of England, but as non-commercial banks these are in any case not relevant to our analysis. CDS is not traded in Clydesdale's name, so we use that of its parent National Australia Bank. We treat RBS and Natwest as a single settlement bank because CDS is not traded in Natwest's name. Finally, we also use Bloomberg to obtain daily values of the Libor (London Interbank Offered Rate), daily values of the CHAPS banks' equity market values, along

\footnotetext{
${ }^{10}$ All commercial CHAPS banks have access to reserve accounts with the Bank of England.

${ }^{11}$ The list of eligible assets is restricted to highly liquid and safe securities, such as high-quality sovereign debt. See Bank of England 2010.
} 
with balance sheet information.

\section{Measuring delay}

CHAPS settlement banks face throughput guidelines during the day. During our sample period, they were expected to make a certain proportion of their daily values by certain times - $50 \%$ by noon and $75 \%$ by $2.30 \mathrm{pm}$. Compliance with these throughput targets may not, however, have been an appropriate measure for delay. First, the guidelines applied only on average over the course of the month. Second, the punishment for deviation may have been seen as weak. This suggests that banks may not have attempted to schedule payments in line with the targets. ${ }^{12}$ Third, the guidelines only related to two moments in time each day. Therefore, to capture delay more accurately, we construct a more 'continuous' measure that adds up the deviations in throughput relative to a pre-crisis benchmark average at many points during the day. We do this by first dividing the day into 62 ten-minute time slots, from $6.00 \mathrm{am}$ to $4.20 \mathrm{pm} .^{13}$

Let $P_{s, t}^{O U T}$ denote the total payment value settled in CHAPS on day $s$ by the end of time-slot $t$. Then throughput by time $t$ on day $s$ is defined as:

$$
x_{t}^{s}=\frac{\sum_{\tau=1}^{t} P_{s, \tau}^{O U T}}{\sum_{\tau=1}^{62} P_{s, \tau}^{O U T}}
$$

The benchmark period consists of the $K=500$ business days between 1 January 2006 and 31 December 2007 inclusive. The benchmark throughput at time-slot $t$ is computed as:

$$
\beta_{t}=\frac{1}{K} \sum_{s=1}^{K} x_{t}^{s}
$$

which is the average daily throughput at time $t$ over the benchmark period. The delay (expressed in minutes) for day $s$, in the post-benchmark period is thus:

$$
d^{s}=\frac{1}{62} \sum_{t=1}^{62}\left(\beta_{t}-x_{t}^{s}\right) \times 620 \text { minutes }
$$

We multiply the deviation in throughput by 620 minutes, the total amount of time CHAPS is in operation daily (from $6.00 \mathrm{am}$ to $4.20 \mathrm{pm}$ ), in order to express the percentage delay in terms of clock time. According to the delay measure $d^{s}$, a $1 \%$ decrease in average daily throughput relative to the benchmark value corresponds to an average aggregate delay of 6.2 minutes. ${ }^{14}$ Positive values signify delay in payments relative to the benchmark period, whereas negative values mean that payment throughput has increased relative to the benchmark period.

Figure 1 shows the delay measured in (3) aggregated across all CHAPS banks over the period from 1 January 2008 to 12 February 2009. The black vertical line marks 15 September 2008, the date of Lehman's default. Following the default of Lehman there is a large increase in payment

\footnotetext{
${ }^{12}$ Banks were required to appear before a 'Star Chamber' and explain their performance. For more information on the enforcement of these guidelines, see Box 3 of Becher et al. 2008.

${ }^{13}$ CHAPS usually closes at $4.20 \mathrm{pm}$ but settlement banks can request an extension which may last up to $7.00 \mathrm{pm}$. This allows them time to deal with operational problems. If an extension was called on a particular day, we cut off at $4.20 \mathrm{pm}$ and look at throughput relative to the total amount paid by $4.20 \mathrm{pm}$.

${ }^{14}$ In other words, if payments are made at a constant rate throughout the day, then one percentage point of deviation from the benchmark throughput is equivalent to every payment being made 6.2 minutes later.
} 
delay. Aggregate delay increases by an average of two standard deviations in the two months following the failure of Lehman Brothers and it peaks on ... at about 25 minutes daily (an increase of three standard deviations). This implies that, at this point, daily payments were on average being made about 25 minutes later than in the benchmark period.

Figure 1: Delay, 1 January 2008 - 12 February 2009. The solid line shows the five-day moving average of aggregate delay (in minutes) in CHAPS payments. The aggregate delay measure is defined in equation (3). The vertical line marks the date of Lehman's default.

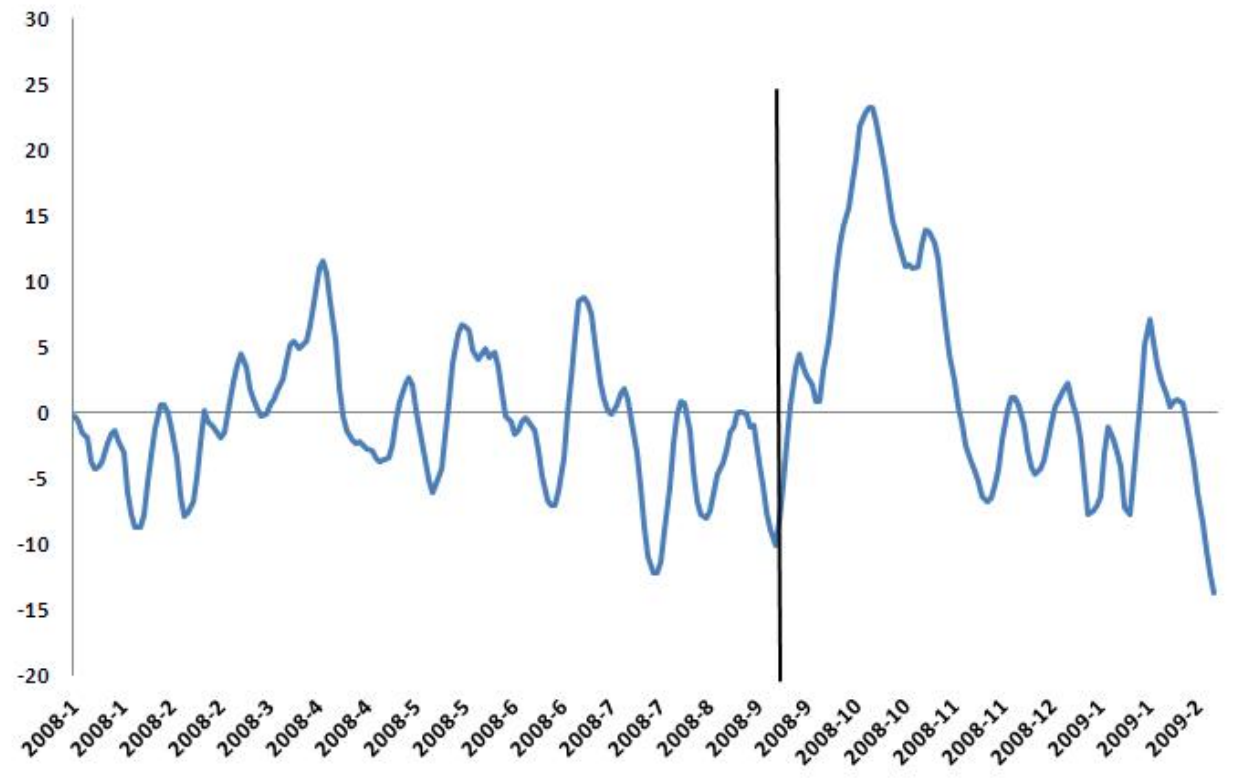

\section{Counterparty risk and delay}

In this section we formally examine whether concerns over counterparty risk were responsible for the observed increase in payment delay following the collapse of Lehman Brothers. A bank might delay a payment to a counterparty if it thinks there is a high chance that the counterparty will default during the day. Even though the bank is obliged to make that payment, it may prefer, in the event of the counterparty defaulting, to net its obligations against incoming payment obligations from the counterparty rather than attempt to recover the money via bankruptcy proceedings. ${ }^{15}$ This intuition suggests that delay should be targeted toward banks that are perceived to be as riskier. For this reason, we construct a bank-specific variable that captures the delay in incoming payments for each bank. The idea is to see whether delay in incoming payments can be explained by the recipient bank's credit risk.

We need to control for other potential determinants of delay. One such factor potentially influencing delay is the general market environment for liquidity. If liquidity is scarce, or if it is expensive, then banks may, ceteris paribus, delay making payments within the day in an attempt

\footnotetext{
${ }^{15}$ Delay in the recovery of money may take the settlement bank below its reserves target, forcing it to borrow overnight on the standing facilities (from the BoE) or the interbank market at a higher rate. Furthermore, during the crisis, use of standing facilities became stigmatised, meaning that the true cost of using them may have been more than just the interest rate paid to the BoE (see Wetherilt et al. 2010).
} 
to use expected incoming payments to fund outgoing ones (see Bech and Garratt, 2003). Of course, not every bank can delay making payments or the system will fall into gridlock. In the wake of the Lehman collapse, sterling liquidity was sufficient to accommodate banks' CHAPS payments (see Benos et al. 2012). Nevertheless, there is also evidence that, during the most intense period of the financial crisis, the cost of obtaining intraday liquidity in sterling rose more than tenfold compared to the pre-crisis levels (see Jurgilas and Zikes, 2012). The cost of intraday liquidity reflected banks' increased opportunity cost of repoing collateral intraday with the Bank of England and thus the increased cost of funding outgoing payments. In our empirical specification, we attempt to explain delay controlling for both the total amount of liquidity available and the overall cost of obtaining liquidity.

\subsection{Empirical Methodology}

\section{Variables}

To assess whether and to what extent concerns over liquidity and/or counterparty default risk can explain payment delay, we first construct a bank-specific delay variable so as to exploit the cross-sectional dimension of our sample. In particular, for each bank we calculate a daily value of delay in incoming payments from the rest of the system, using a variation of equation (3). Let $x_{i, t}^{s}$ denote the fraction of all incoming payments to bank $i$ that are completed on day $s$ by the end of time $t$ and let $\beta_{i, t}$ be the bank $i$ benchmark throughput defined as:

$$
\beta_{i, t} \equiv \frac{1}{K} \sum_{s=1}^{K} x_{i, t}^{s}
$$

where, as with the aggregate delay measure, the benchmark period consists of the $K=500$ business days between 1 January 2006 and 31 December 2007 inclusive. We then measure the delay in incoming payments to bank $i$ on day $s$ by:

$$
\text { Delay }_{i, s} \equiv \frac{1}{62} \sum_{t=1}^{62}\left(\beta_{i, t}-x_{i, t}^{s}\right) \times 620 \text { minutes }
$$

As with the aggregate delay measure, positive values of Delayi,s mean that bank $i$ receives payments from the rest of the system with a delay relative to the benchmark period, whereas negative values mean that it receives payments faster.

To assess the impact of liquidity constraints, we condition delay on both the total amount of liquidity available among CHAPS banks and also the cost of liquidity. We capture the amount of liquidity available to banks sending payments to bank $i$ on day $s$ by the variable $L_{i q_{-i, s}}$ which is defined as:

$$
\text { Liq }_{-i, s} \equiv \sum_{j \neq i}\left[\text { Reserves }_{j, s}+{\text { BoE } \left.\text { Collateral }_{j, s}\right]}\right.
$$

i.e. it is the sum of reserves and the amount of eligible collateral posted with the Bank of England by banks other than bank $i$ on day $s$. To proxy for the cost of liquidity, we use the spread between the overnight Libor and the BoE policy rate $\left(L_{i b S p r}\right)$. Although the Libor spread captures the cost of unsecured overnight lending, this is strongly correlated with the cost of intraday secured lending (see Jurgilas and Zikes, 2012) which is the rate that matters in our case. 
To capture counterparty credit risk, we use the banks' 5-year CDS premia (in \%). We use the 5-year CDS premium because this is the most liquid term and therefore should have a value which most accurately reflects the market view of default risk (see Mengle 2007). Of course, these premia are based on 5-year contracts and as such they reflect the market's expectation about the probability of default over a 5-year horizon. This is, in principle, problematic because daily payment behavior will most likely be influenced by concerns of immediate credit risk. On the other hand, the period over which we do our estimation was marked by elevated concerns over credit risk and thus it could be argued that changes in the 5-year premia largely reflect shifts in perceptions about probability of default in the near term. In any case, we carry out robustness checks in which we use instead a Merton-type model to estimate a default probability to capture credit risk, instead of using CDS premia (see Section 5.2).

We also condition delay on the total value of all day $s$ payments made by the sending banks $\left(P m t_{-i, s}\right)$ measured in £billions. That is, if $P_{j, s}^{O U T}$ are the payments made by bank $j$ on day $s$, the control variable is defined as:

$$
P m t_{-i, s} \equiv \sum_{j \neq i} P_{j, s}^{O U T}
$$

This variable aims to capture potential effects arising due to internal bilateral limits or compliance with throughput requirements. If bilateral limits exist and are binding, then a larger daily amount of outgoing payments could mean that these limits are hit earlier and so some of the payment orders will be executed later in the day. Alternatively, if banks are concerned about leaving large payment values to the end of the day, they may try to process a larger proportion of payments early. In addition, if larger payments tend to be more time-sensitive, then a large value of payouts may be associated with less delay. ${ }^{16}$ Table 1 shows the summary statistics of the variables used in the empirical specification.

Table 1: Summary statistics of the variables used in our empirical tests. The time horizon is 15 September 2008 to 12 February 2009. "Delay" (measured in minutes) is the delay in the daily incoming payments to each of the panel banks and is defined in equation (5). "CDS" is the premium (in \%) of the 5-year CDS contract written on the senior debt of each panel bank. "Libor" is the daily average overnight borrowing rate (in \%) and " $B o E$ " is the daily Bank of England policy rate (in \%). "Liquidity ( Liq)" is the daily liquidity available (in £billions) of the rest of the banks making payments to a given panel bank and is defined in equation (6). "Payments (Pmt)" is the total amount (in £billions) paid by all banks sending payments to a given panel bank and is defined in equation (7).

\begin{tabular}{c|ccccc}
\hline \hline & $\begin{array}{c}\text { Delay } \\
(\text { mins })\end{array}$ & $\begin{array}{c}\text { CDS } \\
(\%)\end{array}$ & $\begin{array}{c}\text { Libor-BoE spread } \\
(\%)\end{array}$ & $\begin{array}{c}\text { Liquidity } \\
(£ b n)\end{array}$ & $\begin{array}{c}\text { Payments } \\
(£ b n)\end{array}$ \\
N & 1,166 & 1,166 & 106 & 1,166 & 1,166 \\
Mean & 4.13 & 1.48 & 0.16 & 46.00 & 248.58 \\
St.Dev. & 33.15 & 0.61 & 0.37 & 7.24 & 44.22 \\
Min & -94.10 & 0.57 & -0.50 & 25.30 & 99.75 \\
Max & 149.60 & 4.86 & 1.79 & 71.48 & 378.66 \\
\hline
\end{tabular}

\footnotetext{
${ }^{16}$ For example, Armantier et al. 2008 find that Fedwire payments tend to settle earlier on days when customer payments are larger.
} 
To assess whether and to what extent delay is explained by concerns over liquidity and/or counterparty risk, we estimate the following baseline panel model:

$$
\begin{aligned}
\text { Delay }_{i, s} & =\sum_{j=1}^{4} b_{j} \text { Delay }_{i, s-j}+c_{1} C D S_{i, s-1}+c_{2} \text { LibSpr }_{s-1}+c_{3} \text { Liq }_{-i, s}+c_{4} \text { Pmt }_{-i, s} \\
& +\sum_{k=1}^{N} d_{k} I_{[k=i]}+\sum_{l=1}^{4} e_{l} I_{[l=s]}+u_{i, s}
\end{aligned}
$$

where $i=1,2, \ldots, N$ denotes first-tier CHAPS banks, $s$ denotes days and $u_{i, s} \sim I I D$. The dependent variable is the delay (in \%) in incoming payments to bank $i$ on day $s$ as defined in equation (5). $C D S_{i, s-1}$ is the one-day lagged value of the individual bank 5-year CDS premium (in \%). We use one-day lagged values for the CDS premium on the assumption that banks are likely to condition their payment behavior on their perception of a counterparty's condition as of the previous day, because yesterday's information has already been disseminated and absorbed by the market. This renders the previous day's values the most relevant measure of counterparties' views of creditworthiness prior to payment timing decisions being made. To capture the determinants of delay after the collapse of Lehman, we estimate this model for the period between 15 September 2008 (Lehman default) to 12 February 2009. ${ }^{17}$

In addition to the other variables, which we have already described, we include four lags of the dependent variable in our specification. This is done to capture autoregressive time-varying effects on delay that would otherwise not be captured by the model. ${ }^{18}$ This also corrects the potential endogeneity bias that may arise when the Libor-BoE rate spread is included as a regressor. ${ }^{19}$ The inclusion of lags of the dependent variable in a fixed-effects panel regression also gives rise to a dynamic bias. ${ }^{20}$ However, our panel is characterised by "small" cross-section (size 11) and "large" time-series (106 days) which means that the dynamic bias should be minimal; we therefore report standard fixed effects estimates. ${ }^{21}$ Finally, we include bank and day-of-the-week dummies to control for unobservable individual bank effects and payment patterns over the course of a week.

\section{Baseline Regression Results}

Table 2 shows the results of a number of estimated specifications based on model (8). The first thing to notice is that all three variables of interest (i.e. 1-Lag "CDS", 1-Lag "Libor-BoE spread" and "Liquidity") have the expected signs and are statistically significant (at least at a 5\% level) in all specifications estimated via fixed effects. In terms of magnitudes, a one standard deviation increase in the CDS premium (or about 0.6 percentage points) is associated with an increase in delay by roughly 2.5 minutes in the full specification (column $(\mathrm{g})) .{ }^{22}$ A one standard deviation

\footnotetext{
${ }^{17}$ We end at 12 February 2009 due to data limitations and the suspension by the BoE of reserves targeting in March 2009, which may be expected to have caused a regime change in banks' payments behavior.

${ }^{18}$ Four is the minimum number of lags required to eliminate the serial correlation in the error terms.

${ }^{19}$ This is because if causality also runs in the opposite direction - i.e. lagged delay influences the cost of liquidity - that would effectively give rise to an autoregressive model for delay.

${ }^{20}$ See Nickell 1981.

${ }^{21}$ The dynamic bias tends to zero as $T \rightarrow \infty$. Accordingly, the Arellano-Bond consistent estimator is almost exactly the same in our case as the simple fixed effects estimator and is therefore omitted.

${ }^{22}$ As Table 1 shows, over the time period we study CDS premia varied from the mean by a substantial number of standard deviations, suggesting that this could have been an economically large effect.
} 
increase in the Libor-BoE spread (or about 0.4 percentage points) causes an increase in delay by five minutes. Finally, a one standard deviation decrease in the amount of liquidity available (or $£ 7.24$ billion) adds 3.2 minutes of delay. ${ }^{23}$ The total amount of payments made is not statistically significant in any of the specifications, meaning that either the internal bilateral limits that banks employ are too high to be binding, or that our variable does a poor job at capturing their effect.

These results are consistent with the theoretical predictions of the literature that payment behavior (in general) and payment timing decisions (in particular) are influenced both by concerns about liquidity and counterparty credit risk. Furthermore, liquidity concerns appear to be associated both with the absolute amount of liquidity available on a given day as well as the cost of obtaining liquidity in the interbank market.

A couple of observations are in order. First, a large fraction of the variation in delay is due to unobservable, time-invariant fixed effects as evidenced by the relatively high $R^{2}$ obtained when delay is conditioned exclusively on its lags and bank fixed effects (column(a)). Our variables of interest collectively and in various combinations increase the $R^{2}$ by about $2-5 \%$ (columns (b) to (e) and $(\mathrm{g})$ ). This suggests that there are important determinants of delay that we fail to explicitly account for in our model. A potential reason for this is that we fail to capture properly the effect of the bilateral limits that CHAPS banks have in place when scheduling payments to one another. ${ }^{24}$ Unfortunately, we do not have the data to explore this further. Second, there are at least two potential sources of bias in our estimations, both associated with measurement errors. The first has to do with the fact that CHAPS is a tiered payment system and as such the ultimate senders and recipients of some of the observed payments are second-tier customer banks that do business through their first-tier CHAPS correspondent banks. These means that payment timing decisions may be affected by the CDS premia of the second-tier banks. The second has to do with the fact that the 5-year CDS premium may be a poor proxy for credit risk over the period of our sample. In the next section we do a series of robustness checks in order to rule out both of these concerns.

Even though a good part in the variation of delay is left unexplained, the estimation results of the baseline specification confirm the theoretical predictions on how concerns about liquidity and counterparty risk should affect the timing of payments in a liquidity-intensive gross-settlement payment system. The results suggest that this may be an important channel through which counterparty risk manifests itself.

\subsection{Robustness tests}

\section{Is tiering an issue?}

CHAPS is a highly tiered payment system, meaning that only a few "first-tier" settlement banks participate directly in it. These banks have settlement accounts at the Bank of England which they use to obtain intraday liquidity. The first-tier banks act as correspondents and facilitate payments for the other "second-tier" banks. Whenever a "second-tier" bank needs to make a payment, it sends a message to its correspondent first-tier bank which in turn makes the payment on its behalf. Similarly, when a second-tier bank is to receive a payment, this is sent to its correspondent bank which nets it against any outstanding obligations by the second-tier bank. Any outstanding net

\footnotetext{
${ }^{23}$ Benos et al. 2012 calculates the monetary cost associated with the risks arising from the interaction of payment delays and operational outages, and thereby assesses in more detail the economic significance of this delay.

${ }^{24}$ The significant drop in $R^{2}$ when the bank fixed effects are excluded (column (f)) appears to confirm this.
} 
Table 2: Delay in incoming payments, baseline specification. We estimate model (8) over the period of 15 September 2008 to 12 February 2009. The dependent variable is "Delay" (in minutes) and is the delay in incoming payments to each bank as defined in equation (5). "CDS" is the premium (in \%) of the 5-year CDS contract written on the senior debt of each panel bank. "Libor" is the average of the announced individual bank overnight borrowing rates (in \%) as reported to the British Bankers' Association each morning. "BoE" is the Bank of England overnight policy rate (in \%). "Liquidity (Liq)" is the daily liquidity available (in £billions) of all banks making payments to a given panel bank and is defined in equation (6). "Payments (Pmt)" is the daily total amount (in £billions) paid by all other banks sending payments to a given panel bank. Robust standard errors are in parentheses. $*$, $* *$ and $* * *$ denote significance at the $10 \%, 5 \%$ and $1 \%$ level respectively.

\begin{tabular}{|c|c|c|c|c|c|c|c|}
\hline $\begin{array}{c}\text { Dependent Variable: } \\
\text { Delay } \\
\end{array}$ & (a) & (b) & (c) & $\overline{(d)}$ & $\overline{(\mathrm{e})}$ & $\overline{(f)}$ & $(\mathrm{g})$ \\
\hline $\begin{array}{c}\text { Independent Variables: } \\
\text { 1-Lag Delay }\end{array}$ & $\begin{array}{c}0.171^{* * *} \\
(0.040)\end{array}$ & $\begin{array}{l}0.168^{* * *} \\
(0.040)\end{array}$ & $\begin{array}{c}0.146^{* * *} \\
(0.040)\end{array}$ & $\begin{array}{c}0.166^{* * *} \\
(0.040)\end{array}$ & $\begin{array}{c}0.147^{* * *} \\
(0.040)\end{array}$ & $\begin{array}{c}0.189^{* * *} \\
(0.041)\end{array}$ & $\begin{array}{c}0.145^{* * *} \\
(0.040)\end{array}$ \\
\hline 2-Lag Delay & $\begin{array}{c}0.138^{* * *} \\
(0.040)\end{array}$ & $\begin{array}{c}0.139^{* * *} \\
(0.040)\end{array}$ & $\begin{array}{c}0.122^{* * *} \\
(0.041)\end{array}$ & $\begin{array}{c}0.140^{* * *} \\
(0.040)\end{array}$ & $\begin{array}{c}0.121^{* * *} \\
(0.041)\end{array}$ & $\begin{array}{c}0.160^{* * *} \\
(0.040)\end{array}$ & $\begin{array}{c}0.122^{* * *} \\
(0.041)\end{array}$ \\
\hline 3-Lag Delay & $\begin{array}{c}0.136^{* * *} \\
(0.038)\end{array}$ & $\begin{array}{c}0.139^{* * *} \\
(0.038)\end{array}$ & $\begin{array}{c}0.136^{* * *} \\
(0.038)\end{array}$ & $\begin{array}{c}0.141^{* * *} \\
(0.038)\end{array}$ & $\begin{array}{c}0.136^{* * *} \\
(0.038)\end{array}$ & $\begin{array}{c}0.178^{* * *} \\
(0.037)\end{array}$ & $\begin{array}{c}0.138^{* * *} \\
(0.038)\end{array}$ \\
\hline 4-Lag Delay & $\begin{array}{l}0.054 \\
(0.037)\end{array}$ & $\begin{array}{l}0.055 \\
(0.036)\end{array}$ & $\begin{array}{c}0.051 \\
(0.036)\end{array}$ & $\begin{array}{l}0.058 \\
(0.036)\end{array}$ & $\begin{array}{l}0.048 \\
(0.036)\end{array}$ & $\begin{array}{l}0.093 \\
(0.037)\end{array}$ & $\begin{array}{l}0.050 \\
(0.036)\end{array}$ \\
\hline 1-Lag $C D S$ & - & - & $\begin{array}{c}4.911^{* * *} \\
(1.864)\end{array}$ & $\begin{array}{c}4.244^{* *} \\
(1.933)\end{array}$ & - & $\begin{array}{l}0.200 \\
(1.350)\end{array}$ & $\begin{array}{c}4.217^{* *} \\
(1.904)\end{array}$ \\
\hline $\begin{array}{l}\text { 1-Lag Libor-BoE } \\
\text { spread }\end{array}$ & - & - & $\begin{array}{c}11.883^{* * *} \\
(2.760)\end{array}$ & - & $\begin{array}{c}12.691^{* * *} \\
(2.739)\end{array}$ & $\begin{array}{c}8.255^{* * *} \\
(2.694)\end{array}$ & $\begin{array}{c}12.679^{* * *} \\
(2.747)\end{array}$ \\
\hline Liquidity & - & $\begin{array}{c}-0.461^{* * *} \\
(0.142)\end{array}$ & - & $\begin{array}{c}-0.420^{* * *} \\
(0.144)\end{array}$ & $\begin{array}{c}-0.485^{* * *} \\
(0.141)\end{array}$ & $\begin{array}{c}-0.333^{* * *} \\
(0.123)\end{array}$ & $\begin{array}{c}-0.443^{* * *} \\
(0.143)\end{array}$ \\
\hline Payments & - & $\begin{array}{c}-0.014 \\
(0.031)\end{array}$ & - & $\begin{array}{c}-0.019 \\
(0.031)\end{array}$ & $\begin{array}{c}-0.032 \\
(0.030)\end{array}$ & $\begin{array}{l}0.014 \\
(0.023)\end{array}$ & $\begin{array}{c}-0.037 \\
(0.031)\end{array}$ \\
\hline Bank Fixed Effects & Yes & Yes & Yes & Yes & Yes & No & Yes \\
\hline$N$ & 1,166 & 1,166 & 1,166 & 1,166 & 1,166 & 1,166 & 1,166 \\
\hline$R^{2}$ & $24 \%$ & $26 \%$ & $27 \%$ & $26 \%$ & $27 \%$ & $22 \%$ & $29 \%$ \\
\hline
\end{tabular}

obligations between the two banks are settled by the end of the day. Thus, first-tier banks effectively extend intraday, unsecured credit to their client second-tier banks. The amount of intraday credit available to second-tier banks is subject to limits which vary from bank to bank. In a few cases, a second-tier bank may have more than one correspondent bank.

The problem that tiering poses to our empirical test is that it is not possible to tell if a given payment received by one of the settlement banks in our sample to that bank, or to one of its secondtier customers. Tiering could be problematic because if payments toward a given settlement bank are delayed because of counterparty risk concerns, it is not clear if this is due to credit risk of the 
settlement bank or credit risk of one of its customers. Thus, the point estimates of the parameters of model (8) could be biased.

To control for this, we estimate an expanded version of model (8) where we also include as regressor a variable ("ClientCDS") that captures the collective credit risk of the second-tier customers of each first-tier settlement bank. In particular, this variable equals the weighted average of the customer banks' CDS premia, where the weighting is based on the absolute size of the second-tier banks' total liabilities. Thus, the specification that we estimate is:

$$
\begin{aligned}
\text { Delay }_{i, s} & =\sum_{j=1}^{4} b_{j} \text { Delay }_{i, s-j}+c_{1} C D S_{i, s-1}+c_{1}^{\prime} \text { ClientCD } S_{i, s-1}+c_{2} \text { LibSpr }_{s-1}+c_{3} \text { Liq }_{-i, s}+c_{4} \text { Pmt }_{-i, s} \\
& +\sum_{k=1}^{N} d_{k} I_{[k=i]}+\sum_{l=1}^{4} e_{l} I_{[l=s]}+u_{i, s}
\end{aligned}
$$

where ClientCD $S_{i, s-1}$ is the one-day lagged, liability-weighted, average CDS premium of the customers of CHAPS bank $i$. The rest of the variables are the same as in the baseline specification. Unfortunately, not all of the customer banks are referenced in CDS contracts and for this reason we restrict our analysis on a subset of CHAPS banks for which all of their second-tier customers have a CDS contract traded in their name. THIS DOESN'T SOUND RIGHT TO ME! LET'S CHAT.

The results of this estimation are shown in Table 3. Controlling for client credit risk does not change in any way either the sign or the significance (at the $5 \%$ level) of the main variables of interest. It is interesting however that the "ClientCDS" variable is not significant in any of the specifications. We believe this is because of the intraday unsecured credit line from its first-tier bank that a second-tier bank benefits from: a bank having scheduled a payment to a second-tier bank will be less concerned about the ability of the second-tier bank to pay back later on in the day, since the payment of the second-tier bank will be made by its correspondent CHAPS bank. Thus the sending bank will, ex ante, have less of an incentive to delay its payment to the secondtier bank, unless of course the first-tier sending bank is also risky. Nevertheless, one might expect CHAPS correspondent banks to monitor the credit condition of their customers and adjust the intraday credit limits accordingly. However, the evidence here suggests that either this adjustment does not take place or that it is insensitive to the customers' credit risk as captured by the CDS premium. $^{25}$

\section{Alternative measure of default risk}

Another potential concern is that the 5-year CDS premium may be an inaccurate measure of counterparty risk of the CHAPS panel banks. This could be because, following the collapse of Lehman, CDS premia did not only reflect the credit risk of the underlying reference entity but also the elevated credit risk of the contract sellers. Typically, sellers of CDS contracts on banks are other financial institutions whose default probability at times of stress is highly correlated with that of the banks being referenced in the CDS contract. ${ }^{26}$ In that case, CDS premia would reflect

\footnotetext{
${ }^{25}$ According to Valukas 2010, Lehman Brothers settlement banks tried to reduce their unsecured intraday exposures to the institution once its financial condition began to deteriorate. However, it may be the case that the Lehman Brothers case was not representative.

${ }^{26}$ Most CDS market activity is concentrated around the so called "G-14" banks who act both as intermediaries and net sellers in the CDS market. These are: Bank of America-Merrill Lynch, BNP Paribas, Citi, Credit Suisse, Deutsche Bank AG, Goldman Sachs \& Co., HSBC Group, J.P. Morgan, Morgan Stanley, The Royal Bank of Scotland Group, Societe General, UBS AG, Wachovia Bank.
} 
Table 3: Tiering robustness check. We estimate model (9) over the period of 15 September 2008 to 12 February 2009. The dependent variable is "Delay" (in minutes) and is the delay in incoming payments to each bank as defined in equation (5). "CDS" is the premium (in \%) of the 5-year CDS contract written on the senior debt of each panel bank. "Client $C D S$ " is the weighted average of the customer banks' CDS premia (in \%), where the weights are based on the absolute size of the customer banks' total liabilities. "Libor" is the average of the announced individual bank overnight borrowing rates (in \%) as reported to the British Bankers' Association each morning. "BoE" is the Bank of England overnight policy rate (in \%). "Liquidity ( Liq)" is the daily liquidity available (in £billions) of all banks making payments to a given panel bank and is defined in equation (6). "Payments (Pmt)" is the daily total amount (in £billions) paid by all other banks sending payments to a given panel bank. Robust standard errors are in parentheses. $*, * *$ and $* * *$ denote significance at the $10 \%, 5 \%$ and $1 \%$ level respectively.

\begin{tabular}{|c|c|c|c|}
\hline $\begin{array}{c}\text { Dependent Variable: } \\
\text { Delay }\end{array}$ & (a) & (b) & (c) \\
\hline $\begin{array}{c}\text { Independent Variables: } \\
\text { 1-Lag Delay }\end{array}$ & $\begin{array}{c}0.274^{* * *} \\
(0.051)\end{array}$ & $\begin{array}{c}0.237^{* * *} \\
(0.052)\end{array}$ & $\begin{array}{c}0.220^{* * *} \\
(0.052)\end{array}$ \\
\hline 2-Lag Delay & $\begin{array}{c}0.153^{* * *} \\
(0.047)\end{array}$ & $\begin{array}{c}0.120^{* *} \\
(0.047)\end{array}$ & $\begin{array}{c}0.112^{* *} \\
(0.046)\end{array}$ \\
\hline 3-Lag Delay & $\begin{array}{c}0.113^{* *} \\
(0.051)\end{array}$ & $\begin{array}{c}0.100^{* *} \\
(0.050)\end{array}$ & $\begin{array}{l}0.091^{*} \\
(0.050)\end{array}$ \\
\hline 4-Lag Delay & $\begin{array}{l}0.060 \\
(0.047)\end{array}$ & $\begin{array}{l}0.036 \\
(0.046)\end{array}$ & $\begin{array}{l}0.032 \\
(0.044)\end{array}$ \\
\hline 1-Lag $C D S$ & $\begin{array}{c}4.533^{* *} \\
(2.210)\end{array}$ & $\begin{array}{c}5.602^{* * *} \\
(2.201)\end{array}$ & $\begin{array}{c}4.376^{* *} \\
(2.199)\end{array}$ \\
\hline 1-Lag Client CDS & $\begin{array}{l}0.127 \\
(3.233)\end{array}$ & $\begin{array}{c}-3.834 \\
(3.532)\end{array}$ & $\begin{array}{c}-4.082 \\
(3.492)\end{array}$ \\
\hline $\begin{array}{l}\text { 1-Lag Libor-BoE } \\
\text { spread }\end{array}$ & - & $\begin{array}{c}10.150^{* * *} \\
(2.458)\end{array}$ & $\begin{array}{c}11.483^{* * *} \\
(2.435)\end{array}$ \\
\hline Liquidity & - & - & $\begin{array}{c}-0.484^{* * *} \\
(0.150)\end{array}$ \\
\hline Payments & - & - & $\begin{array}{c}-0.015 \\
(0.030)\end{array}$ \\
\hline $\begin{array}{c}\text { Bank Fixed Effects } \\
N \\
R^{2}\end{array}$ & $\begin{array}{c}\text { Yes } \\
612 \\
34 \%\end{array}$ & $\begin{array}{l}\text { Yes } \\
612 \\
36 \%\end{array}$ & $\begin{array}{c}\text { Yes } \\
612 \\
37 \%\end{array}$ \\
\hline
\end{tabular}

the joint probability of default of both the reference entity and the contract seller (see Giglio 2012). Additionally, counterparty risk in derivatives markets is likely closely related to liquidity risk. If, for instance, major dealers attempt to minimise counterparty risk by limiting their exposures 
to individual counterparties, then, in aggregate, they will limit their overall capacity to provide liquidity. This an area of ongoing research but some early findings point to that direction. For example, Lesplingart et al. 2012 find that controlling for counterparty risk, liquidity risk was priced and increased during the financial crisis for a sample of European corporate CDS contracts.

For these reasons, we also use an alternative Merton-type default risk measure to capture counterparty risk. ${ }^{27}$ This measure is based on the observed values of debt and equity of the CHAPS panel banks and as such does not suffer from the above limitations. In the Appendix we explain in detail how we construct this variable, but the intuition behind this risk measure, due to Merton 1974, is to view the value of a bank's equity as a call option on the bank's assets with the strike price being equal to the value of the bank's liabilities. In this framework, one can use the Black-Scholes 1973 option pricing approach to back out the likelihood that the value of assets drops below the value of debt (i.e. the bank defaults and equity holders are eliminated as residual claimants to the bank's assets.).

We thus estimate model (8) again but substitute the "CDS" spread with the first difference in the Merton default risk indicator ( $\Delta$ Merton"). We use the first difference as a regressor in order to avoid spuriousness in our results as the default risk indicator itself has a unit root. Table 4 shows the results of this estimation. ${ }^{28}$ In all specifications, the variable " $\Delta$ Merton" is statistically significant and positive, at least at the $5 \%$ level. Depending on the specification, a one standard deviation increase in the " $\Delta$ Merton" variable $(2 \%)$ is associated with a 1-2 minute increase in delay in incoming payments, for a given CHAPS bank, relative to the benchmark period throughput.

The impact of a one standard deviation increase in " $\Delta$ Merton" appears to be smaller in magnitude than that of the "CDS" spread (1-2 minutes versus 2-3 minutes). However, the effect of " $\triangle$ Merton" on delay is not directly comparable with that of the "CDS" spread. Unlike the "CDS" spread, the " $\Delta$ Merton" variable does not capture the actual level of the Merton-type default risk measure. The positive coefficient on "Merton" simply suggests that increases in this risk measure are associated with higher absolute levels of delay regardless of the level of the "Merton" variable. It is likely for this reason that the magnitude of the effect is smaller than in the case of the "CDS" spread. The other variables in the specification retain their expected signs and significance.

\section{Turnover}

In CHAPS, banks can reduce their liquidity needs by recycling incoming payments from others. A measure of how successful settlement banks are, in aggregate, at recycling liquidity is "turnover": the average number of times each pound of liquidity provided by a bank to make payments is used during the day. More precisely, turnover is calculated as the ratio of the total value of payments made to the total amount of liquidity employed. Liquidity employed by an individual bank at a given point in time is measured by its net debit position. Thus, if $P_{i, s, t}^{O U T}, P_{i, s, t}^{I N}$ are the payments that bank $i$ makes and receives respectively on day $s$ and during time slot $t$, then the aggregate turnover on day $s$ is given by:

\footnotetext{
${ }^{27}$ We thank Harrison Hong for this suggestion.

${ }^{28}$ This estimation does not use data from the Bank of Scotland/HBOS. HBOS was acquired by Lloyds during the sample period and therefore there is an incomplete set of publicly traded equity prices to use in the construction of the "Merton" default risk indicator.
} 
Table 4: Alternative default risk measure robustness check. We estimate model (8) over the period of 15 September 2008 to 12 February 2009. The dependent variable is "Delay" (in minutes) and is the delay in incoming payments to each bank as defined in equation (5). "CDS" is the premium (in \%) of the 5-year CDS contract written on the senior debt of each panel bank. " $\Delta M e r t o n "$ is the change in the default likelihood indicator of each panel bank as defined in equation (14) in the Appendix. "Libor" is the average of the announced individual bank overnight borrowing rates (in \%) as reported to the British Bankers' Association each morning. "BoE" is the Bank of England overnight policy rate (in \%). "Liquidity (Liq)" is the daily liquidity available (in £billions) of all banks making payments to a given panel bank and is defined in equation (6). "Payments (Pmt)" is the daily total amount (in $£$ billions) paid by all other banks sending payments to a given panel bank. Robust standard errors are in parentheses. ${ }^{*}, * *$ and ${ }^{* * *}$ denote significance at the $10 \%, 5 \%$ and $1 \%$ level respectively.

\begin{tabular}{|c|c|c|c|c|c|}
\hline $\begin{array}{c}\text { Dependent Variable: } \\
\text { Delay }\end{array}$ & (a) & (b) & (c) & (d) & (e) \\
\hline $\begin{array}{c}\text { Independent Variables: } \\
\text { 1-Lag Delay }\end{array}$ & $\begin{array}{c}0.152^{* * *} \\
(0.043)\end{array}$ & $\begin{array}{c}0.149^{* * *} \\
(0.043)\end{array}$ & $\begin{array}{c}0.129^{* * *} \\
(0.044)\end{array}$ & $\begin{array}{c}0.185^{* * *} \\
(0.045)\end{array}$ & $\begin{array}{c}0.131^{* * *} \\
(0.044)\end{array}$ \\
\hline 2-Lag Delay & $\begin{array}{c}0.132^{* * *} \\
(0.044)\end{array}$ & $\begin{array}{c}0.133^{* * *} \\
(0.044)\end{array}$ & $\begin{array}{c}0.116^{* * *} \\
(0.044)\end{array}$ & $\begin{array}{c}0.170^{* * *} \\
(0.043)\end{array}$ & $\begin{array}{c}0.117^{* * *} \\
(0.044)\end{array}$ \\
\hline 3-Lag Delay & $\begin{array}{c}0.101^{* *} \\
(0.040)\end{array}$ & $\begin{array}{c}0.103^{* * *} \\
(0.040)\end{array}$ & $\begin{array}{c}0.100^{* *} \\
(0.040)\end{array}$ & $\begin{array}{c}0.147^{* * *} \\
(0.040)\end{array}$ & $\begin{array}{c}0.101^{* * *} \\
(0.040)\end{array}$ \\
\hline 4-Lag Delay & $\begin{array}{l}0.060 \\
(0.040)\end{array}$ & $\begin{array}{l}0.061 \\
(0.039)\end{array}$ & $\begin{array}{l}0.053 \\
(0.039)\end{array}$ & $\begin{array}{c}0.103^{* * *} \\
(0.039)\end{array}$ & $\begin{array}{l}0.047 \\
(0.038)\end{array}$ \\
\hline 1- $\operatorname{Lag} C D S$ & - & $\begin{array}{c}4.484^{* *} \\
(2.016)\end{array}$ & $\begin{array}{c}4.739^{* *} \\
(2.014)\end{array}$ & - & - \\
\hline 1-Lag $\Delta$ Merton & $\begin{array}{c}99.330^{* * *} \\
(38.176)\end{array}$ & $\begin{array}{c}95.329^{* * *} \\
(37.981)\end{array}$ & $\begin{array}{c}79.296^{* *} \\
(27.974)\end{array}$ & $\begin{array}{c}80.248^{* *} \\
(39.795)\end{array}$ & $\begin{array}{c}61.924^{* *} \\
(32.562)\end{array}$ \\
\hline $\begin{array}{l}\text { 1-Lag Libor-BoE } \\
\text { spread }\end{array}$ & - & - & $\begin{array}{c}11.199^{* * *} \\
(2.934)\end{array}$ & $\begin{array}{c}8.295^{* * *} \\
(2.917)\end{array}$ & $\begin{array}{l}12.258^{* * *} \\
(0.456)\end{array}$ \\
\hline Liquidity & - & - & - & $\begin{array}{c}-0.199 \\
(0.135)\end{array}$ & $\begin{array}{c}-0.450^{* * *} \\
(0.149)\end{array}$ \\
\hline Payments & - & - & - & $\begin{array}{l}0.003 \\
(0.024)\end{array}$ & $\begin{array}{c}-0.055 \\
(0.032)\end{array}$ \\
\hline $\begin{array}{c}\text { Bank Fixed Effects } \\
N \\
R^{2}\end{array}$ & $\begin{array}{c}\text { Yes } \\
1,020 \\
24 \%\end{array}$ & $\begin{array}{c}\text { Yes } \\
1,020 \\
24 \%\end{array}$ & $\begin{array}{c}\text { Yes } \\
1,020 \\
26 \%\end{array}$ & $\begin{array}{c}\text { No } \\
1,020 \\
22 \%\end{array}$ & $\begin{array}{c}\text { Yes } \\
1,020 \\
27 \%\end{array}$ \\
\hline
\end{tabular}




$$
\text { TURNOVER }_{s}=\frac{\sum_{i=1}^{N} \sum_{t=1}^{62} P_{i, s, t}^{O U T}}{\sum_{i=1}^{N} \max \left\{\max _{T}\left[\sum_{t=1}^{T}\left(P_{i, s, t}^{O U T}-P_{i, s, t}^{I N}\right)\right], 0\right\}}
$$

One indication that behavioral changes by banks following the collapse of Lehman had significant economic consequences is seen by examining changes in turnover over the crisis period. The fiveday moving average of this series is shown in Figure 2. Before the collapse of Lehman Brothers, CHAPS settlement banks were able to complete an aggregate daily value of payments that was on average fifteen times as large as the amount of liquidity employed. After the default of Lehman Brothers, the same ratio fell to an average value of eleven. This was a significant change empirically $(\mathrm{p}$-value $=0.00)$ and economically; it represents a drop of almost 30\%. Figure 2 also shows that the breakdown in coordination persisted even as throughput improved from November 2008. This suggests that, although counterparty risk concerns subsided, banks failed to revert immediately to the level of coordination they had prior to the Lehman default.

In any case, the observed breakdown in coordination that was associated with the increase in payment delay after Lehman's default is consistent with the idea of banks delaying payments due to concerns about counterparty risk. Intuitively, if banks delay payments due to concerns about counterparty risk, then their delay should be targeted toward those banks that are perceived to be riskier. This, in turn, would disrupt the payment coordination of banks and would cause them to become less efficient in recycling liquidity as exemplified by the sharp reduction in turnover.

Figure 2: Aggregate turnover in CHAPS, 1 January 2008 - 12 February 2009. Turnover is the ratio of total payments made to the amount of liquidity used on a given day and captures the extent to which banks coordinate their payments. It is defined in equation (10). The vertical line marks the date of Lehman's default.

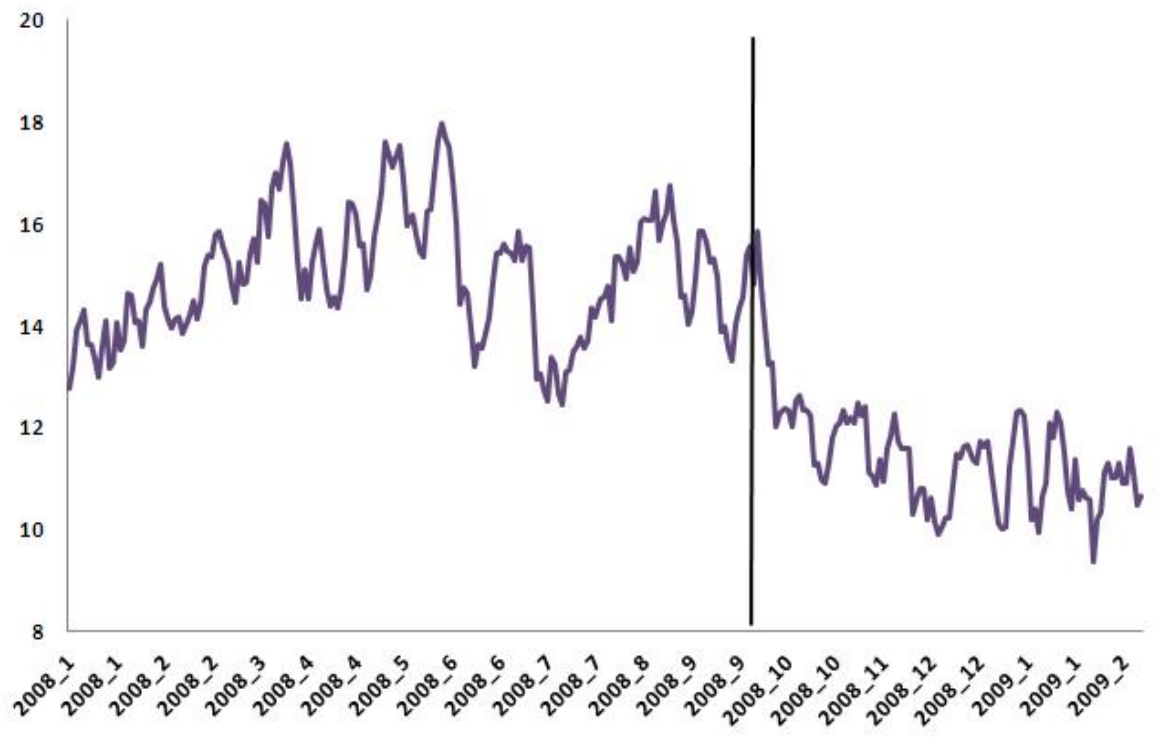

\section{Concluding remarks}


Our analysis reveals a dramatic slowdown in payment processing behavior by CHAPS banks following the collapse of Lehman brothers. After controlling for other potential factors that might influence payment processing behavior, we find that a significant role was played by heightened counterparty risk. This identifies another channel, distinct from the more obvious interbank lending channel, through which fears of insolvency may impact financial markets.

An interesting avenue of future research would be to further explore the broader economic consequences of delay. As mentioned in the introduction, there was an immediate drop in turnover associated with the slowdown in payment processing that followed the collapse of Lehman. This is consistent with the fact that some CHAPS banks were perceived to be at greater risk of failure than others, meaning processing delay was not uniform across the system. This could lead to a situation where some banks were forced to use more of their own liquidity to make payments rather than wait for incoming payments that were being delayed. However, the slowdown in payment processing that was observed following the collapse of Lehman was rather short-lived. Figure 1 shows that by the end of November 2008, there is no discernable difference between the pre-and post Lehman delay measure. In contrast, however, turnover did not return to the pre-crisis level. This could be because a large increase in system reserves reduced the opportunity cost of making payments with own versus recycled liquidity, but we cannot be sure. ${ }^{29}$ Further analysis is needed to resolve this interesting turnover puzzle.

\section{Appendix: Construction of the Merton default likelihood indicator}

Here we describe how we construct the default likelihood indicator (the "Merton" variable) that we use as an alternative proxy for counterparty risk in our empirical specification. We use the approach followed by Vassalou and Xing 2004 which in turn is very similar to the one developed by Moody's KMV. These approaches to modeling default risk are based on the intuition of Merton 1974 where the value of a firm's equity is viewed as a call option on the firm's assets, with the strike price being equal to the firm's liabilities. Furthermore, the value of the firm's assets is assumed to follow a geometric Brownian motion:

$$
d V_{A}=\mu V_{A} d t+\sigma_{A} V_{A} d W
$$

where $V_{A}$ denotes the firm's assets, $\mu$ is the drift of the process, $\sigma_{A}$ is the instantaneous volatility of the asset value and $W$ is a standard Wiener process.

In this setup, the market value of the firm's equity is given by the Black-Scholes 1973 option pricing formula:

$$
V_{E}=V_{A} N\left(d_{1}\right)-X e^{-r T} N\left(d_{2}\right)
$$

where

$$
d_{1}=\frac{\ln \left(V_{A} / X\right)+\left(r+\frac{1}{2} \sigma_{A}^{2}\right) T}{\sigma_{A} \sqrt{T}}, \quad d_{2}=d_{1}-\sigma_{A} \sqrt{T}
$$

with $N$ denoting the cumulative standard normal distribution, $X$ being the value of debt, $r$ being the risk-free interest rate and $T$ denoting the average debt maturity. Since default occurs whenever

\footnotetext{
${ }^{29}$ Aggregate reserves increased threefold, while liquidity usage declined (Benos et al. 2012). The increase in liquidity available can be attributed to the Bank of England's quantitative easing policy from March 2009 which increased the amount of reserves in the system. To accommodate this, the Bank of England suspended the reserves targeting regime, allowing banks to increase their reserves holdings without incurring charges (Bank of England 2010). The decline in usage also corresponded to an overall decline in payment activity in part because banks did not need to enter the money markets to manage their reserves to the target.
} 
the value of assets drops below the value of debt, the probability at time $t$ of this event occurring sometime in the next $T$ periods will be:

$$
\operatorname{Pr}(\text { default })_{t}=\operatorname{Pr}\left(V_{A, t+T} \leq X_{t}\right)
$$

One can then show that the probability of default equals: ${ }^{30}$

$$
\operatorname{Pr}(\text { default })_{t}=N\left(-\frac{\ln \left(V_{A, t} / X_{t}\right)+\left(\mu-\frac{1}{2} \sigma_{A}^{2}\right) T}{\sigma_{A} \sqrt{T}}\right)
$$

This is the "Merton" variable whose first difference we use in our empirical specification. More specifically, we estimate daily values of this quantity, for all CHAPS panel banks, for the period between 15 September 2008 and 12 February 2009. Since we wish to capture short-term credit risk than that implied by the 5-year CDS premium, we set the time horizon for the expiration of the call option to one year. Thus, $X$ is the book value of bank liabilities that fall due within a year. For this, we use the Bloomberg variable "Short term borrowings". This variable includes all liabilities that are due within a year, but also the short-term portion of all longer term liabilities, such as interest payments on long-term debt. $V_{A}$ is backed out from the Black-Scholes equation (12). We use the one-year UK government borrowing rate as the risk-free rate. The drift $\mu$ is the moving average of the past 1-year daily returns on the value of assets; these past 1-year asset values have also been calculated via equation (12) using past 1-year daily equity returns.

Backing out the implied and unobserved $V_{A}$ 's from the observed $V_{E}$ 's requires knowledge of $\sigma_{A}$. To estimate and update $\sigma_{A}$, we follow an iterative approach similar to that in Vassalou and Xing 2004. The process involves the following steps:

1. For each of the days that we want to estimate $\sigma_{A}$, we use daily stock returns over the previous year and estimate instead $\sigma_{E}$, which is set as the initial value of $\sigma_{A}$ in the iterative process.

2. Using $\sigma_{E}$ as an estimate for $\sigma_{A}$ in the Black-Scholes equation (12), we calculate an initial set of values of $V_{A}$ for each of the days of the previous year.

3. We then compute the daily returns implied by the $V_{A}$ s and their variance $\sigma_{A}$ over the same one-year period.

4. The new value of $\sigma_{A}$ is then used again in equation (12) to repeat the above process.

5. The iteration stops when the distance between two consecutive values of $\sigma_{A}$ is less than $10^{-4}$.

Once we obtain the converged value of $\sigma_{A}$, we use it to back out the $V_{A}$ 's through equation (12) as described above. As Vassalou and Xing also report, in practice, it takes about three to four iterations for the values of $\sigma_{A}$ to converge.

\section{References}

Armantier, O., J. Arnold, and J. McAndrews. 2008. "Changes in the Timing Distribution of Fedwire Funds Transfers." Federal Reserve Bank of New York Economic Policy Review 14(2): 83-112.

Bank of England. 2009. Payment Systems Oversight Report 2008.

\footnotetext{
${ }^{30}$ See Vassalou and Xing 2004.
} 
Ball, A., E. Denbee, M. Manning and A. Wetherilt. 2011. "Intraday liquidity: risk and regulation." Bank of England Financial Stability paper, No. 11.

Bank of England. 2010. The framework for the Bank of England's operations in the sterling money markets.

Bech, M. and R. Garratt. 2003. "The intraday liquidity management game." Journal of Economic Theory 109(2): 198-219.

Bech, M. and R. Garratt. 2012. "Illiquidity in the interbank payment system following widescale disruptions." Journal of Money, Credit and Banking 44(5): 903929

Becher, C., M. Galbiati and M. Tudela. 2008. "The timing and funding of CHAPS Sterling payments." Federal Reserve Bank of New York Economic Policy Review 14(2): 113-33.

Benos, E., R. Garratt and P. Zimmerman. 2012. "Bank behaviour and risks in CHAPS following the collapse of Lehman Brothers." Bank of England Working Paper No. 451.

Black, F. and M. Scholes. 1973. "The pricing of options and corporate liabilities." Journal of Political Economy 81: 637-659

Galbiati, M. and K. Soramäki. 2011. "An agent-based model of payment systems." Journal of Economic Dynamics and Control 35(6): 859-875

Giglio, S. 2012. "Credit Default Swap Spreads and Systemic Financial Risk", working paper, Booth School of Business, University of Chicago

Heider, F., M. Hoerova and C. Holthausen. 2009. "Liquidity hoarding and interbank market spreads: the role of counterparty risk." European Central Bank Working Paper No. 1126

Jurgilas, M. and F. Zikes. 2012. "Implicit intraday interest rate in the UK unsecured overnight money market." Bank of England Working Paper No. 447

Lesplingart C., M. Christophe and M. Petitjean. 2012. "Liquidity and CDS premiums on European companies around the subprime crisis", Review of Derivatives Research 15(3): 257-281

Manning M., E. Nier and J. Schanz. 2009. "The economics of large-value payments and settlement: theory and policy issues for central banks." Oxford University Press.

Mengle, D. 2007. "Credit derivatives: an overview." Federal Reserve Bank of Atlanta Economic Review 92(4).

Merton, R. 1974. "On the pricing of corporate debt: The risk structure of interest rates." Journal of Finance 29: 449-470

Nickell, S. J. 1981. "Biases in dynamic models with fixed effects." Econometrica 49(6): 141726. 
Singh, M. and J. Aitken. 2009. "Counterparty Risk, Impact on Collateral Flows and Role for Central Counterparties." IMF Working Paper No. 09/173

Valukas, A. R. 2010. Lehman Brothers Holdings Inc. Chapter 11 Proceedings examiners report. U.S. Bankruptcy Court Southern District of New York, Jenner and Block LLP, Section III.A.5.

Vassalou, M. and Y. Xing. 2004. "Default Risk in Equity Returns." Journal of Finance 59: 831-868

Wetherilt, A., P. Zimmerman and K. Soramäki. 2010. "The sterling unsecured loan market during 2006-2008: insights from network theory." Bank of England Working Paper No. 398. 